\title{
Features and impact of trust-based relationships between community health workers and low-income pregnant women with chronic health conditions: A focus group study
}

\author{
Lisa M. Boyd ( $\sim$ lisa.boyd@yale.edu ) \\ Yale University School of Medicine https://orcid.org/0000-0001-9702-679X \\ Renee Mehra \\ Yale University School of Public Health \\ Jordan Thomas \\ University of California Los Angeles \\ Jessica Lewis \\ Yale University \\ Shayna Cunningham \\ Yale University School of Public Health
}

\section{Research article}

Keywords: Community health workers, lay health workers, pregnancy support, maternal health, trustbased relationships, chronic disease, vulnerable populations

Posted Date: August 24th, 2019

DOI: https://doi.org/10.21203/rs.2.13556/v1

License: (c) (i) This work is licensed under a Creative Commons Attribution 4.0 International License.

Read Full License 


\section{Abstract}

Background Pregnancy can be a particularly stressful time for women with underlying chronic conditions. Chronic health conditions such as hypertension, cardiovascular disease, and diabetes are associated with obstetric morbidity and mortality and poor birth outcomes, and are becoming more prevalent among pregnant women in the United States. In light of the American Public Health Association's call to increase the reach of community health worker (CHW) interventions, the aim of this paper is to better understand how to effectively support women with chronic disease during pregnancy by examining the impact of CHW support from the perspective of pregnant women.Methods Clients and CHWs were recruited from three community-based organizations in the eastern United States running Merck for Mothers-funded interventions to support pregnant women in urban settings. Nine focus groups and eight interviews were conducted with 40 low-income clients with chronic conditions and $18 \mathrm{CHWs}$ and program staff. Focus group and interview data were analyzed using grounded theory-informed thematic analysis.Results Clients reported that $\mathrm{CHWs}$ contributed to their well-being during pregnancy in numerous ways and credited CHWs with improvements in mental health and health behaviors. Services like providing guidance around nutrition appeared to play a role in improving client management of chronic disease. CHWs' ability to build trust-based relationships through emotional attendance, authenticity, and prioritization of clients' needs facilitated the stress reduction and salubrious behavioral change reported by clients.Conclusions $\mathrm{CHWs}$ provide care for the whole woman during pregnancy, an approach that is unique within healthcare and confers multiple benefits. $\mathrm{CHW}$ intervention is particularly valuable for women facing challenges such as chronic disease and limited access to resources. Additional municipal, state, and federal resources should be devoted to expanding programs that provide vulnerable mothers with comprehensive care.

\section{Introduction}

Pregnancy can be a stressful time, particularly for women with underlying health conditions and limited access to social and economic resources. Not only are chronic conditions such as hypertension, cardiovascular disease, and diabetes associated with adverse maternal and neonatal health outcomes, but the prevalence of these conditions is increasing among pregnant women in the United States [1]. In addition, prevalence of these conditions is graded by socioeconomic status, with the highest rates occurring among low-income women [1]. On the other hand, pregnancy is a time when women are highly motivated to improve their health behaviors to achieve the best possible outcomes for themselves and their babies [2], making the perinatal period an important "window of opportunity" for health promotion [3].

Although many women engage frequently with health systems during pregnancy, not all do: From 1995 to 2002 , an average of $11.2 \%$ of women who gave birth in the US received inadequate prenatal care as measured by the Adequacy of Prenatal Care Utilization Index [4]. Many factors underlie this care utilization gap, including women's personal feelings about the pregnancy, lack of logistical support, and service provision issues, including perceived caregiver insensitivity [5-7]. An integrative review of 
women's experiences with prenatal care in the US identified provider relationships as the most critical aspect of care for many women [8]. This emphasis on the importance of relationships is also supported by research suggesting that authentic relationships in care management (i.e., those characterized by genuineness, a sense of security, and temporal continuity) benefit patients with chronic conditions by empowering them to take a more active role in their care [9].

Community health worker (CHW) interventions represent a promising strategy to reduce the incidence and impact of chronic disease during pregnancy and improve quality of care, particularly among low-resource women. $\mathrm{CHWs}$ are lay health workers trained in health promotion and healthcare interventions who are members of, or closely connected to, the communities they work with [10]. In general, CHW duties include brokering access to medical services and educational resources, fostering health education and selfsufficiency, and providing material resources with the goal of improving client's quality of life through personal connection and assistance [10].

Reviews of $\mathrm{CHW}$ interventions aimed at improving quality of care and health outcomes have found them to be effective for health initiatives such as cardiovascular disease risk reduction [11, 12], cancer prevention [12], and diabetes education and management [13]. In addition, they have been associated with improved infant health outcomes [14]. Because of the client-focused, community-centric nature of $\mathrm{CHW}$ interventions, they may be uniquely effective at reaching vulnerable populations [15], and studies using national medical claims data suggest that efforts to improve care coordination during pregnancy targeting patient comorbidity may be cost-effective $[16,17]$, as well. CHW intervention during pregnancy therefore presents an ideal opportunity to address chronic health conditions and meet the "triple aim" of enhancing healthcare quality, improving health outcomes, and reducing costs [18].

Despite the potential benefits of CHW intervention, there is a paucity of research on how CHWs can help pregnant women with chronic conditions have healthier pregnancies, with much of the research in this area focusing exclusively on doula support. Several states have expanded Medicaid coverage for doula services [19-21] based on research documenting benefits of continuous labor care for pregnant and postpartum women $[22,23]$. Although doulas and CHWs both provide support to women during pregnancy, doula services are typically confined to active labor and the immediate postpartum period [24]. CHWs are therefore better positioned to meet the needs of the whole woman during the perinatal period and to address health disparities in maternal health and birth outcomes. Given that approximately four million women give birth in the US each year [25], the current lack of research on CHW pregnancy support represents a meaningful gap in the maternal care literature.

Additional research is also needed to determine which aspects of the $\mathrm{CHW}$-client relationship are most salient for encouraging positive change [26, 27]. Evaluation metrics for $\mathrm{CHW}$-client relationship are often limited to number and type of interactions with little regard for more subjective-but equally importantmetrics like the quality of the bond between the health worker and client. Documenting and understanding these less tangible aspects of successful $\mathrm{CHW}$-client interactions is essential to 
understanding what makes $\mathrm{CHW}$ models effective and vital for the expanded implementation of these programs.

\section{The Present Study}

As part of a 10-year, $\$ 500$ million global initiative to address maternal mortality, Merck for Mothers is supporting three innovative CHW models in the US to link pregnant women with chronic conditions to care and support services they need to have safe pregnancies and healthy lives. The objectives of this study were to identify specific features of the $\mathrm{CHW}$-client relationship that facilitate these goals and to examine the impact of the program on clients. Given recent media attention to very high rates of maternal mortality in the U.S. [28], the findings of this study will be useful to inform the expansion of communitybased care, including how to best help CHWs be effective in improving maternal health for low-income women with chronic conditions.

\section{Methods}

\section{Study Design}

This qualitative study uses data from three clinical sites in the eastern U.S. implementing the Merck for Mothers-sponsored CHW programs. Clients at the study sites were primarily low-income women of color of childbearing age with chronic conditions. Table 1 provides details regarding the target population, program objectives, enrollment criteria, and $\mathrm{CHW}$ activities at each site. At one community-based organization, CHWs served as both patient advocates and birth doulas, supporting women during pregnancy and the postpartum period. CHWs at another community-based organization used a specialized curriculum to educate pregnant and recently postpartum women about managing their chronic conditions and to support them with reproductive life planning. The third site, a Medicaid accountable care organization, targeted all women of reproductive age, using CHWs to support women's reproductive life planning and ensure they received both prenatal and primary care. CHWs at each site were extensively trained to help women manage chronic conditions and other social and medical challenges that affect health.

\section{[Table 1 about here]}

\section{Data Collection}

Approximately one-year post-implementation, 9 focus groups (2-4 per site) were conducted with CHWs (n $=18)$ and clients $(n=32)$. CHW and client focus groups were conducted separately. An additional 8 semistructured interviews were conducted with clients who were unable to attend focus group sessions (total client $n=40$ ). 
All CHWs were invited to participate in focus groups. Former and current clients of the study sites who were 18 years of age or older were contacted by CHWs or other program staff to invite them to participate. Verbal informed consent was obtained from all participants prior to the beginning of each focus group and interview. Focus groups were moderated by two-person teams comprised of a research assistant with a background in psychology (the third author) and a postdoctoral associate or faculty member with a background in sociology or social psychology (the first author or former research group Principal Investigator, respectively). Interviews with Spanish- and French-speaking participants were conducted by a Spanish-speaking Latina research collaborator and a French-speaking team member (the second author), respectively. The team was open about team member backgrounds, roles in the study, and intentions, and communicated these with staff at each site prior to site visits.

Focus group guides were developed to address key questions and provide guidelines for probing beyond these broad questions. Topics covered during client focus groups and interviews included: how participants learned about and decided to enroll in their respective CHW programs; client's experiences working with CHWs (e.g., what a typical encounter looked like, ways in which their health needs and social needs were and were not met); extent to which client's health behaviors and experiences with healthcare providers changed as a result of interactions with their $\mathrm{CHW}$; and strengths and weaknesses of the CHW program with which the client was involved. Community health workers were asked to reflect on their experiences working with clients, the healthcare team, and community providers. Each participant received a $\$ 20$ Walmart gift card as compensation for their time and transportation to the focus group.

Focus group sessions and interviews were audio recorded and subsequently transcribed by members of the research team. Audio files were stored on a secure server. The study was deemed exempt under 45 CFR 46.101(b)(2) by the Yale School of Medicine Institutional Review Board.

\section{Data Analysis}

Data were analyzed using a grounded theory-informed thematic approach. Interview guides addressed specific key themes, with additional themes developed during analysis of the focus group and interview data. All transcripts were coded by the primary analyst using an open coding scheme, with a subset of transcripts also coded by a second analyst. As part of open coding, the analysts wrote memos that captured coding decisions, identified key concepts in the data, and drew connections between transcripts. Open codes were then consolidated into a smaller number of thematic codes. The coding scheme was reviewed and revised by all authors collectively. Coding and analysis were carried out using DEDOOSE qualitative analytic software [29]. Best practices for qualitative research were employed, including searching for disconfirming evidence, interviewing multiple respondents at each site for triangulation, and maintaining an audit trail to document analytic decisions.

\section{Results}


Results are organized into two main sections. The first main section discusses salient qualities of the $\mathrm{CHW}$-client relationship and is comprised of three sections describing sub-themes that emerged for the core concept "building trust-based relationships." The second main section describes the numerous ways this trust-based relationship impacted the health and well-being of clients.

\section{Salient Aspects of the CHW-Client Relationship}

Many participants used words such as "trust" and "like family" to describe their relationships with CHWs, attesting to the closeness of the connections formed over the course of the $\mathrm{CHW}$ intervention. Three key sub-themes emerged as critical to the formation of meaningful CHW-client connections: emotional attendance, authenticity, and prioritization of clients' needs.

\section{Sub-theme 1: Emotional attendance}

Emotional attendance took many forms in CHW-client interactions: Clients consistently reported that they formed strong personal bonds with CHWs as a result of CHWs' "emotional support,"

"listening/communication," and "just being there." For some mothers, a shared emotional and spiritual connection was comforting. This connection was particularly important for clients with few other sources of support.

That's the biggest part for me, that she's there for me mentally, she's there for me emotionally and in some ways, on a spiritual connection we can converse, we can connect. And that's the biggest thing for me...the spiritual part. It helps keep you grounded, and in your struggles, I'm not by myself anymore. (Client, Philadelphia)

Other clients reported receiving affirmation or reassurance around stressful issues, and in some cases credited the $\mathrm{CHW}$ with preventing the onset of postpartum depression. Many participants explicitly discussed the value of talking through problems with their $\mathrm{CHW}$, and of $\mathrm{CHWs}$ being good listeners. This open communication served to not only strengthen the $\mathrm{CHW}$-mother bond, but also relieved stress and provided comfort.

She came ... to make sure I was ok, to make sure I wasn't stressed, to make sure I didn't go through postpartum [depression]. And she basically did all of those things and plus a little more. You know, whenever I needed to talk she was there to listen. (Client, Philadelphia)

Me having multiple kids at home, I don't wanna be in depression or stressed out, you know, when I give birth. So being able to talk about some of the issues that I'm dealing with that are personal and she's like, "I'll help you with that," "We can research this together," "We can do this together," you know, "I'Il try to figure it out with you," "You're not alone." (Client, Philadelphia) 
For the subsample of immigrant clients, who generally reported feeling isolated in a US context, CHW companionship was an especially important aspect of care.

If they [CHWs] were not there... really, today, it would be better for me to go back to my own country, even if I suffer there, than to stay here. Because she really helps a lot. Yeah. If you have them, you do not have your mom, your dad, you will be satisfied, you will not even know that you are lacking something because you have someone to talk to at any time when you have the need to share something. Human beings cannot hold everything inside, it must often be shared and she [the CHW] is there. They really listen and they give advice. (Client, New York City)

CHWs recognized the importance of fostering trust and reported being very deliberate in how they built rapport with clients. They emphasized taking specific, intentional measures to establish an open and comfortable environment with clients, who, in turn, reported $\mathrm{CHWs}$ took a genuine interest in their lives and were "easy to talk to."'

You gotta understand that some of the moms are already being dictated and told what to do and how to do it. And they're tired. They are tired of hearing it.... When we sit there, we sit back and just pause for a moment and just listen to them. It makes them feel comfortable.... So I think those doors are open when you sit back and just not try to dictate and tell them what to do. (Community health worker, Philadelphia)

She was really pleasant and awesome... it's hard to stick with someone, especially in situations where you need help, you need... someone to talk to, and you need to be directed to the right places, and she was just extremely easy to talk to... I think that was probably the best part. Like, I was extremely comfortable. (Client, Camden)

In general, the benevolent behaviors on the part of $\mathrm{CHWs}$ characterized here as 'emotional attendance' led clients to trust and feel comfortable with CHWs, which in turn enabled future interactions that more firmly established trust and closeness. This positive feedback loop, in which the trustee consistently meets or exceeds the expectations of the trustor, forms the basis of trust development in interpersonal relationships [30].

\section{Sub-theme 2: Authenticity}

By definition, CHWs are members of and/or have an unusually close understanding of the community they serve. Several CHWs in this study discussed similarities between themselves and their clients. Their motivation to engage in this work stemmed, in part, from this shared understanding with clients.

We kill ourselves with our clients. We have to love what we do to continue to do it. Because we ourselves have trouble feeding our families. So we are not too farfetched from the clients that we help. We don't do this because we are going to get rich. We do this because we love it. (Community health worker, New York) 
CHWs were described by clients as being authentic, selfless, and compassionate. Their consistent understanding and patience showed clients that they were motivated by a desire to help them achieve their goals, rather than by self-interest. This was particularly meaningful for women who had felt judged by providers in the past.

... it's not like she [the CHW] feels pressured to do it.. I mean she volunteers to help. When you don't have nobody in your corner, when you don't have no support system, this like goes a long way. She's helped me in numerous ways that I needed. (Client, Philadelphia)

... never once did it [participating in the CHW program] make me feel like less of a woman or less of a mom for coming from that background [history of substance use]. That's a huge thing. You can ask any addict like just someone treating you like a totally normal person... it makes a world of difference. (Client, Camden)

\section{Sub-theme 3: Prioritization of clients' needs}

CHWs' scope of practice addresses a broad range of pregnant women's medical and social needs (i.e., instrumental, informational, emotional). Clients' needs determined the services provided, and CHWs were described as going "above and beyond" to help their clients in any way possible. The prioritization of clients' needs and flexibility in services offered based on those needs were factors mothers talked about as helping them build close, trusting relationships with $\mathrm{CHWs}$.

She helps with everything, it's amazing. It's a really good service, it's for the people. (Client, Camden)

Clients described CHWs as always being present with them-whatever else they might have going on, the client felt like the CHW was fully there to support her:

She never came sad. She's always happy, always smiling. She never let her outside business interfere with us.... (Client, Camden)

CHWs' flexibility and availability -their willingness to work around a client's schedule, meet her anywhere she needed, and let her needs and priorities determine the content and timing of interactions-reinforced the sense that the client was the CHW's top priority.

... What makes this program work for me is they adjust to my schedule. Like if she's [the CHW is] like, "Oh well what's best for you, you wanna go meet here? I can meet you." They'll come and meet you at your appointments and everything. (Client, Philadelphia)

\section{CHW Impact}

Women have diverse medical, as well as social and psychological, needs during pregnancy. The support they received from $\mathrm{CHWs}$ fell into three broad categories-instrumental, informational, and emotional- 
and, according to clients, resulted in greater engagement with the healthcare system, improved health behaviors, and reduced stress.

Multiple clients reported that CHWs provided material goods they needed for their baby or other children when obtaining those things themselves would have been burdensome or unfeasible. Such items included diapers, breast pumps, clothing, car seats, toys, and furniture.

When the baby was in the hospital, it was like 12 days, they went to my house and brought me a crib, a stroller, they brought me a car seat because I didn't have one. They brought me baby bottles, clothes. I didn't have any of that. (Client, New York City)

Beyond the provision of material goods, CHWs supported timely and appropriate access to care by assisting clients with scheduling and attending medical appointments, including by accompanying them to visits or facilitating transportation. Some clients reported that their $\mathrm{CHW}$ reminded them to adhere to medication regimens.

'Cause there is a lot of women out there that could need a little push. That's what it is too, it's like a push for us. Her [CHW] making our appointments. Her calling us. If she didn't do that I would never show up. (Client, Camden)

I have seizures. And I was kinda like, I don't even know how to say it, neglecting them? Like, putting them off? Cause they're not like...[a] major issue and once I got pregnant, um... the neurologist I usually go to was a little far, and she [CHW] helped me find a neurologist that was closer. (Client, Camden)

CHWs were also instrumental in helping clients obtain important documentation, such as birth certificates and personal identification cards, and apply for jobs and stable housing.

And they're [CHWs] not there to just help with the baby. They help you with your other children, they help you with other things you need. Like other issues you have in life and that's like, that's what I really like most about the program. (Client, Philadelphia)

I ask them what are the three goals that they [clients] would like to work on as part of the program. So, if it's housing or something like that, we'll look for it on Craigslist, different ads, or we'll get one of our housing specialists to come out and help them.... We'll connect them to social services so they can get income, social security cards, or certificates.... (Community health worker, Camden)

CHWs provided health education and skills-building to empower clients to better manage their chronic health conditions and improve their health behaviors. Topics covered included nutrition, physical activity, breast feeding, medications, and self-care.

They've [CHWs] offered me nutrition classes and I've come to those. They also support you with breastfeeding. I have changed the way l eat thanks to one of those programs they offer... They had one about juices, juices and soda. Wow. I learned a lot of things that day that I had no clue about. After that 
day, I tried to drink more natural juices.... And water, lots of water. No soda, in our house we don't drink soda. We have made a lot of changes.... And for her [daughter], for her when she grows up she knows how to eat right. (Client, New York City)

I'm happy with it [CHW program] because it has helped me a lot. I have maintained my blood sugar because it was very high and she taught me about vegetables and stuff." (Client, New York City)

Clients universally described feeling that CHWs were always there for them, especially in times of need, which in turn enabled them to take steps to address stressors they faced in daily life.

... she make me feel so, so, so, so secure and that I have somebody to talk to and somebody to help me out. And really, really looking out like [for me], like I never thought [possible] before. So yeah I feel very, very confident that we're gonna get, I'm gonna get my stuff done, my stuff together. (Client, Philadelphia)

Many women expressed a desire to continue communicating with their $\mathrm{CHW}$ indefinitely, a testament to the high value women placed on relationships with $\mathrm{CHWs}$.

I'm really grateful. Because it [the CHW program] has helped a great deal. And I'm gonna say this for the record, [CHW] has been my rock for the past five months. And I hope, you know even I don't know how long the program runs for, but I always want her to be a part of my life. (Client, Philadelphia)

Regardless of the duration, $\mathrm{CHWs}$ and clients viewed their relationships as having long- lasting impacts.

Because we not only impact the women, but the family as a whole. And it's also work that is generational. What we teach them, they go and they teach their daughters or their sons or another family member. So we not only touch them, but we touch everybody else that they touch. And that's what makes me want to do this kind of work. (Community health worker, New York City)

...it is like a dose of courage that we come to get [from CHWs] every week to continue for the rest of the week, to confront other things and matters of everyday life that they would not be able to manage by themselves. And every week, we are in a hurry to come and give an account of what we have done, how we have improved. And each one of us today can remember her first day here, in which condition she came in, and where she is at today... we really feel an improvement, not only in terms of health or maternal protection but in terms of the overall living environment. (Client, New York City)

\section{Discussion}

Reports from the Institute of Medicine (2015) and the Agency for Healthcare Research and Quality (2009) have recommended expanded use of $\mathrm{CHWs}$ as a vital strategy to improve health behaviors and more effectively link vulnerable people to healthcare [31, 32]. In addition, previous studies have demonstrated that authentic healing relationships improve outcomes among patients with comorbid chronic conditions [9]. This study identified specific features of the CHW-client relationship that facilitate this process for pregnant women, including emotional attendance, authenticity, and prioritization of clients' needs. Both 
clients and community health workers view $\mathrm{CHW}$ programs as an approach that mitigates the burden of life stressors on pregnant and postpartum women, and supports the development of health-promoting habits during pregnancy and post-birth.

This study's findings are consistent with research indicating that a personal connection with healthcare providers is particularly important for pregnant women [8], patients with chronic conditions [9], and lowincome populations [33]. Trust was a central aspect of the $\mathrm{CHW}$-client relationships reported on in this study and clients were deeply impacted by their relationships with $\mathrm{CHWs}$. The qualities that were found to contribute to the formation of trusting relationships-emotional attendance, authenticity, and prioritization of clients' needs-are often lacking in healthcare settings [8,34,35,36], and their absence jeopardizes the potential benefits of the provider-client relationship [8]. In particular, one study found an association between patients' perceptions of provider empathy and patient enablement-that is, the ability to understand and effectively cope with a chronic condition [37]. For pregnant women with chronic conditions, a sense of enablement, or agency, is key to developing health-promoting behaviors.

In Novick's integrative review of women's experiences with prenatal care in the US, relationships with providers were found to be of primary importance [8]. Women reported frustration and low levels of satisfaction with care when care was impersonal-for example, when they were not listened to, were treated like a "number," or were "shrugged off" by providers [8, p. 232]. Lay health workers helped address unmet relational needs in the context of care by showing caring, alleviating stress by helping with nonmedical problems, sharing experiences, and spending time with women. Results from the current study showing that $\mathrm{CHW}$ services were perceived by mothers as unanimously positive and beneficial echo Novick's findings and reinforce the idea that the standard definition of care should include emotional and social support and respect for the whole woman-even if these needs get met through ancillary care by $\mathrm{CHWs}$ and others in the healthcare system.

The breadth of services provided by CHWs is unique and reflects a philosophy of putting patients' needs first. The client-driven structure of the $\mathrm{CHW}$ program upends the hierarchical relationship typically enacted between providers and patients, in which the provider is an authority figure who advises and directs the patient. In that traditional model, input on treatment flows in one direction and patients sometimes find interactions to be mechanistic and impersonal [8]. In the CHW-client model, the client's needs guide the intervention, with bi-directional communication creating trust-reinforcing feedback loops between the CHW and client. Each step of the intervention is personalized to the woman's circumstances, and client buy-in is essential to success because the interpersonal relationship between provider and patient is the engine of change. As the evidence base for this care model grows, the same tenets and principles that guide CHW-involved care-emotional attendance, authenticity, and prioritization of clients' needs-may serve as an exemplar for transforming traditional care relationships between providers and patients.

This study has limitations. The participants were women who were actively engaged in CHW programs. The experiences described may not apply outside of the urban settings studied or for women who had 
access to, but may have been less engaged with, the $\mathrm{CHW}$ programs assessed. In the analysis, thematic saturation was achieved among English-speaking participants. Due to relatively small numbers of Spanish- and French-speaking clients, it is unlikely that data saturation was achieved for these women. Observations from immigrant mothers that were discussed across language groups were included. However, specific groups of immigrants may experience challenges with the US healthcare system and derive benefits from relationships with $\mathrm{CHWs}$ not captured in this paper. Nonetheless, this study contributes to a growing body of literature demonstrating that support provided by $\mathrm{CHWs}$ and other lay health workers is beneficial to pregnant women and provides insights into the mechanisms by which CHWs are effective.

\section{Conclusion}

CHWs serve women in multiple capacities, providing instrumental, informational, and emotional support. The roles adopted by these lay care providers, and the meaningful impact of their contributions as reported by mothers, highlight the numerous unmet needs of low-income pregnant women with chronic health conditions. The results show that $\mathrm{CHWs}$ are effective atbuilding meaningful, trust-based relationships with patients, that those relationships enable the prioritization of the mother's health, and that mothers perceive these relationships as leading to improvements in stress levels, emotional wellbeing, health behaviors, and life circumstances.

Beyond the individual-level benefits derived for clients, the use of support personnel during pregnancy is likely to be cost-saving for state Medicaid programs [38]. Future studies that examine the costeffectiveness of $\mathrm{CHW}$ interventions targeting pregnant and postpartum women should include metrics to assess the quality of $\mathrm{CHW}$-client interactions to ensure their greatest potential impact. Additional research is also needed to determine best practices for sustainable funding of $\mathrm{CHW}$ interventions so that more women may benefit from such support.

\section{List Of Abbreviations}

CHW: Community health worker

\section{Declarations}

Ethics approval and consent to participate: The study was deemed exempt under 45 CFR 46.101(b)(2) by the Yale School of Medicine Institutional Review Board. Participants provided verbal consent prior to data collection.

Consent for publication: Not applicable.

Availability of data and materials: Coding scheme is available from the corresponding author upon reasonable request. 
Declaration of competing interests: The authors declare that they have no competing interests.

Funding: This research was supported by funding from Merck Sharp and Dohme to Shayna D. Cunningham and by funding from the National Institute of Mental Health of the National Institutes of Health to the Center for Interdisciplinary Research on AIDS at Yale University under training grant number T32MH020031-18, with Lisa M. Boyd as recipient. The content is solely the responsibility of the authors and does not necessarily represent the official views of the National Institutes of Health.

Authors' contributions: LB conceptualized the article. LB and RM developed the coding scheme with input from JT and SC. LB, RM, JT, JL, and SC contributed to the development of the article. All authors read and approved the final manuscript.

Acknowledgements: We would like to extend our thanks to the participating program staff at the Camden Coalition of Healthcare Providers, Maternity Care Coalition, and Northern Manhattan Perinatal Partnership, and our heartfelt gratitude to the program clients and community health workers who participated in this study.

\section{References}

1. Admon LK, Winkelman TN, Moniz MH, Davis MM, Heisler M, Dalton VK. Disparities in chronic conditions among women hospitalized for delivery in the United States, 2005-2014. Ob Gyn. 2017;130(6):1319-26.

2. Phelan S. Pregnancy: a "teachable moment" for weight control and obesity prevention. Am J Ob Gyn. 2010;202(2):135-e1.

3. Kershaw TS, Magriples U, Westdahl C, Rising SS, Ickovics J. Pregnancy as a window of opportunity for HIV prevention: effects of an HIV intervention delivered within prenatal care. Am J Pub Health. 2009;99(11):2079-86.

4. Partridge S, Balayla J, Holcroft CA, Abenhaim HA. Inadequate prenatal care utilization and risks of infant mortality and poor birth outcome: a retrospective analysis of 28,729,765 US deliveries over 8 years. Am J Perinatol. 2012;29(10):787-94.

5. Loveland Cook CA, Selig KL, Wedge BJ, Gohn-Baube EA. Access barriers and the use of prenatal care by low-income, inner-city women. Social Work. 1999;44(2):129-39.

6. Daniels P, Noe GF, Mayberry R. Barriers to prenatal care among Black women of low socioeconomic status. American Journal of Health Behavior. 2006;30(2):188-98.

7. Downe S, Finlayson K, Walsh D, Lavender T. 'Weighing up and balancing out': a meta-synthesis of barriers to antenatal care for marginalised women in high-income countries. BJOG. 2009;116(4):518-29. 
8. Novick G. Women's experience of prenatal care: an integrative review. J Midwifery Womens Health. 2009;54:226-237.

9. Grinberg C, Hawthorne M, LaNoue M, Brenner J, Mautner D. The core of care management: the role of authentic relationships in caring for patients with frequent hospitalizations. Population Health Management. 2016;19(4):248-56.

10. American Public Health Association. Support for community health workers to increase health access and to reduce health inequities. Policy. 2009;20091. Available from: https://www.apha.org/policies-andadvocacy/public-health-policy-statements/policy-database/2014/07/09/14/19/support-for-communityhealth-workers-to-increase-health-access-and-to-reduce-health-inequities

11. Brownstein JN, Bone LR, Dennison CR, Hill MN, Kim MT, Levine DM. Community health workers as interventionists in the prevention and control of heart disease and stroke. Am J Prev Med. 2005;29(5):128-33.

12. Kim K, Choi JS, Choi E, Nieman CL, Joo JH, Lin FR, Gitlin LN, Han HR. Effects of community-based health worker interventions to improve chronic disease management and care among vulnerable populations: a systematic review. Am J Pub Health. 2016;106(4):e3-28.

13. Norris SL, Chowdhury FM, Van Le K, Horsley T, Brownstein JN, Zhang X, Jack Jr L, Satterfield DW. Effectiveness of community health workers in the care of persons with diabetes. Diabet Med. 2006;23(5):544-56.

14. Lewin S, Munabi-Babigumira S, Glenton C, Daniels K, Bosch-Capblanch X, van Wyk BE, OdgaardJensen J, Johansen M, Aja GN, Zwarenstein M, Scheel IB. Lay health workers in primary and community health care for maternal and child health and the management of infectious diseases. Cochrane database of systematic reviews. 2010;17(3):CD004015.

15. Swider SM. Outcome effectiveness of community health workers: an integrative literature review. Public Health Nursing. 2002;19(1):11-20.

16. Cunningham SD, Magriples U, Thomas JL, Kozhimannil KB, Herrera C, Barrette E, Shebl FM, Ickovics JR. Association between maternal comorbidities and emergency department use among a national sample of commercially insured pregnant women. Academic Emergency Med. 2017;24(8):940-7.

17. Cunningham SD, Herrera C, Udo IE, Kozhimannil KB, Barrette E, Magriples U, Ickovics JR. Maternal medical complexity: impact on prenatal health care spending among women at low risk for cesarean section. Womens Health Issues. 2017;27(5):551-8.

18. Berwick DM, Nolan TW, Whittington J. The triple aim: care, health, and cost. Health Affairs. 2008;27(3):759-769. 
19. Minnesota Dept of Human Services. Provider manual: doula services. Feb 29 2016. Available from: http://www.dhs.state.mn.us/main/idcplg? IdcService = GET_DYNAMIC_CONVERSION\&

RevisionSelectionMethod $=$ LatestReleased\&dDocName $=$ dhs16_190890\#P40_2113

20. Oregon Health Authority. Oregon Medicaid reimbursement for doula services. Sept 12 2018. Available from: https://www.oregon.gov/oha/HSD/OHP/Tools/Oregon\%20Medicaid\%

20reimbursement\%20for\%20doula\%20services.pdf

21. Gentry QM, Nolte KM, Gonzalez A, Pearson M, Ivey S. "Going beyond the call of doula": a grounded theory analysis of the diverse roles community-based doulas play in the lives of pregnant and parenting adolescent mothers. Journal Perinat Ed. 2010;19(4):24-40.

22. Hans SL, Edwards RC, Zhang Y. Randomized controlled trial of doula-home-visiting services: impact on maternal and infant health. Mat Child Health J. 2018;22(1):105-13.

23. Mehra R, Cunningham SD, Lewis JB, Thomas JL, Ickovics JR. Recommendations for the pilot expansion of Medicaid coverage for doulas in New York State. Am J Pub Health. 2019;109(2):217-19.

24. Gruber KJ, Cupito SH, Dobson CF. Impact of doulas on healthy birth outcomes. J Perinat Educ. 2013;22(1):49-58.

25. Martin JA, Hamilton BE, Osterman MJK, Driscoll AK, Drake P. Births: final data for 2017. Natl Vital Stat Reports. Hyattsville, MD: National Center for Health Statistics. 2018;67(8).

26. Mundorf C, Shankar A, Peng T, Hassan A, Lichtveld MY. Therapeutic relationship and study adherence in a community health worker-led intervention. J Community Health. 2017;42(1):21-9.

27. Lichtveld MY, Shankar A, Mundorf C, Hassan A, Drury S. Measuring the developing therapeutic relationship between pregnant women and community health workers over the course of the pregnancy in a study intervention. J Community Health. 2016;41(6):1167-76.

28. Martin N, Montagne R. The last person you'd expect to die in childbirth. Propublica/NPR. May 12 2017. Available from: https://www.propublica.org/article/die-in-childbirth-maternal-death-rate-health-caresystem

29. Dedoose Version 8.0.35 [Web application for qualitative and mixed method data software]. 2018. Los Angeles CA: SocioCultural Research Consultants, LLC. Available from: www.dedoose.com

30. Mayer RC, Davis JH, Schoorman FD. An integrative model of organizational trust. Academy Management Rev. 1995;20(3):709-34.

31. Pittman M, Sunderland A, Broderick A, Barnett K. Bringing community health workers into the mainstream of US health care. NAM Perspectives. Feb 4 2015. Available from: https://nam.edu/wpcontent/uploads/2015/06/chwpaper3.pdf 
32. Viswanathan M, Kraschnewski J, Nishikawa B, Morgan LC, Thieda P, Honeycutt A, Lohr KN, Jonas D. Outcomes of community health worker interventions. Evidence report/technology assessment. 2009;181:1-44. Available from:

https://www.ahrq.gov/downloads/pub/evidence/pdf/comhealthwork/comhwork.pdf

33. Bassuk EL, Perloff JN, Mickelson KD, Bisseil HD. Role of kin and nonkin support in the mental health of low-income women. Am J Orthopsychiatry. 2002;72(1):39-49.

34. Hickson GB, Clayton EW, Entman SS, Miller CS, Githens PB, Whetten-Goldstein K, Sloan FA. Obstetricians' prior malpractice experience and patients' satisfaction with care. JAMA. 1994;272(20):1583-7.

35. Reynolds WJ, Scott B. Do nurses and other professional helpers normally display much empathy? J Adv Nursing. 2000;31(1):226-34.

36. Jangland E, Gunningberg L, Carlsson M. Patients' and relatives' complaints about encounters and communication in health care: evidence for quality improvement. Patient Educ Counseling. 2009;75(2):199-204.

37. Mercer SW, Watt GC, Reilly D. Empathy is important for enablement. BMJ. 2001;322(7290):865.

38. Kozhimannil KB, Hardeman RR, Alarid-Escudero F, Vogelsang CA, Blauer-Peterson C, Howell EA. Modeling the cost-effectiveness of doula care associated with reductions in preterm birth and cesarean delivery. Birth. 2016;43(1):20-7.

\section{Table 1}

: CHW Intervention Site Profiles 


\begin{tabular}{|c|c|c|c|}
\hline $\begin{array}{l}\text { of } \\
\text { ization }\end{array}$ & $\begin{array}{l}\text { Community-based } \\
\text { organization }\end{array}$ & $\begin{array}{l}\text { Community-based } \\
\text { organization }\end{array}$ & $\begin{array}{l}\text { Medicaid accountable care } \\
\text { organization }\end{array}$ \\
\hline $\begin{array}{l}\mathrm{t} \\
\text { ation }\end{array}$ & $\begin{array}{l}\text { Pregnant women with chronic } \\
\text { health conditions }\end{array}$ & $\begin{array}{l}\text { Pregnant and postpartum } \\
\text { women with chronic } \\
\text { conditions }\end{array}$ & $\begin{array}{l}\text { Medically and socially complex } \\
\text { women of reproductive age }\end{array}$ \\
\hline $\begin{array}{l}\text { am } \\
\text { ives }\end{array}$ & $\begin{array}{l}\text { Securely connect women to } \\
\text { medical care through } \\
\text { pregnancy and } \\
\text { postpartum/interconceptually, } \\
\text { by both addressing social } \\
\text { barriers as identified by } \\
\text { individualized service plans } \\
\text { and connecting women to } \\
\text { care postpartum }\end{array}$ & $\begin{array}{l}\text { Deliver program } \\
\text { components to all } \\
\text { enrollees, including } \\
\text { individual support and } \\
\text { goal-setting activities, } \\
\text { group health education } \\
\text { sessions, and six-week } \\
\text { chronic disease self- } \\
\text { management workshop } \\
\\
\text { Improve women's health } \\
\text { and wellness and } \\
\text { efficacy regarding her } \\
\text { reproductive life and } \\
\text { health }\end{array}$ & $\begin{array}{l}\text { Provide comprehensive } \\
\text { interconception care, } \\
\text { operationalized as reconnecting } \\
\text { women to primary care after a } \\
\text { pregnancy and before they may } \\
\text { become pregnant again and } \\
\text { connection to existing community } \\
\text { resources } \\
\text { Work alongside the patient on } \\
\text { goals they have identified as } \\
\text { priority }\end{array}$ \\
\hline $\begin{array}{l}\text { ment } \\
\text { a. }\end{array}$ & $\begin{array}{l}\text { Pregnant with chronic health } \\
\text { conditions (e.g., diabetes, } \\
\text { hypertension, obesity, mental } \\
\text { health, substance abuse, } \\
\text { IPV); and missed prenatal } \\
\text { appointment(s) }\end{array}$ & $\begin{array}{l}\text { History of pregnancy } \\
\text { complications; a } \\
\text { diagnosis of } \\
\text { hypertension, diabetes or } \\
\text { another chronic health } \\
\text { condition; or overweight }\end{array}$ & $\begin{array}{l}\text { Substantial medical complexity; } \\
\text { documented mental illness or } \\
\text { substance use disorder; } \\
\text { documented social barriers (e.g., } \\
\text { unstable housing, lack of social } \\
\text { support, language barriers, } \\
\text { mobility barriers, past trauma, } \\
\text { labeled as "non-compliant" in } \\
\text { medical record) }\end{array}$ \\
\hline ies & $\begin{array}{l}\text { Support chronic } \\
\text { disease self-management } \\
\text { Refer and connect to } \\
\text { insurance, benefits (e.g., } \\
\text { WIC, food stamps) and } \\
\text { other services } \\
\text { Doula services (e.g., } \\
\text { labor and breastfeeding } \\
\text { support) }\end{array}$ & $\begin{array}{l}\text { Navigation and } \\
\text { coordination } \\
\text { assistance with } \\
\text { clinical care and } \\
\text { social service needs } \\
\text { Escorts to visits } \\
\text { with clinical care } \\
\text { providers and social } \\
\text { services processes } \\
\text { (e.g., homeless } \\
\text { services) }\end{array}$ & $\begin{array}{l}\text { Care coordination and } \\
\text { reconnection to primary care } \\
\text { Link patients to community } \\
\text { resources and benefits (e.g., } \\
\text { transportation, housing, WIC, } \\
\text { Medicaid) } \\
\text { Accompany patients to } \\
\text { appointments both medical } \\
\text { and social }\end{array}$ \\
\hline & $\begin{array}{l}\text { Coordinate care } \\
\text { (including prenatal) and } \\
\text { connect to PCP, } \\
\text { behavioral health and } \\
\text { pediatric care } \\
\text { Education around safe } \\
\text { sleep, healthy nutrition, } \\
\text { birth and family planning, }\end{array}$ & $\begin{array}{l}\quad \text { Provide needed } \\
\text { baby items through } \\
\text { a community closet, } \\
\text { giveaways from } \\
\text { partners, or } \\
\text { referrals to external } \\
\text { organizations }\end{array}$ & $\begin{array}{l}\text { Help clients set } \\
\text { health/social goals } \\
\text { Education around } \\
\text { reproductive health and } \\
\text { pregnancy (e.g., pregnancy } \\
\text { spacing, Reproductive Life } \\
\text { Planning) }\end{array}$ \\
\hline
\end{tabular}


parenting, prenatal and emergency care utilization

- Establish health goals and family supports

- Screen for maternal depression/mental health issues
- One-on-one health education and support via home and office visits

- Discuss reproductive life planning

- Birth and postpartum doula care (as provided by separate party) 